the two-odd problem before they learned others. Specifically, it may be seen that three of the Ss responded correctly at a high level to the diamonds in the initial fifth of training, but their performances when the crosses were odd were much poorer in the initial fifth of training. The remaining $S$ responded correctly initially at a higher level to the crosses than to the diamonds. The data suggest that all Ss learned to respond to the odd diamonds or the odd crosses at different rates. It is suggested that the monkeys did not use oddity as the basis for responding in the early phases of the two-odd problem. The relatively low amount of transfer from the two-odd to the learning-set problems suggests that an incomplete mastery of the oddity principle was evident at the conclusion of two-odd training. It is perhaps unfortunate that the present work reinforced a triangle in the one-odd problem; this may have contributed to a preference for the triangular portion of the diamonds in the two-odd problem resulting in the initial high level of correct responding by three of the Ss when the diamonds were odd.

It should be noted that had the monkeys not shown the different rates of acquisition to the odd diamond and odd cross configurations in the two-odd problem, one would still be unable to state conclusively that the Ss had the oddity principle. It could be argued that the Ss learned the specific stimulus configurations with equal facility.

Figure 1 suggests that brightness was not a variable in acquisition of the two-odd configurations. However, significant differences in the number of errors as a function of position of the odd object on the tray were seen. The center position was associated with the most errors, and the fewest errors were made when the odd object was in the left position. However, no significant differences in errors as a function of stimulus position were seen in oddity-set learning or the oddity-set problems with midproblem reversals of the odd object. French (1965) summarized several studies that suggest that the center position of the odd object is associated with the most errors; however, he also cited studies where the center position had no effect. It may be that the extensive training of the $S s$ in the present study enabled them to develop efficient visual scanning techniques, thereby reducing the number of errors at the center position.

\section{REFERENCES}

FRENCH, G. M. Associative problems. In A. M. Schrier, H. F. Harlow, and F. Stollnitz (Eds.), Behavior of nonhuman primates Vol. 1. New York: Academic Press, 1965. Pp. 167-209.

LEVINE, M., \& HARLOW, H. F. Learning sets with one- and twelve-trial oddity problems. American Journal of Psychology, 1959, 72 253-257.

LEVINSON, B. Oddity learning set and its relation to discrimination learning set. (Doctoral dissertation, University of Wisconsin) Ann Arbor, Mich: University Microfilms, 1958. No. 58-7507.

SIEGEL, S. Nonparametric statistics for the behavioral sciences New York: McGraw-Hill, 1956.

SOBINSON, E. W. A preliminary experiment on abstraction in a monkey. Journal of Comparative Psychology, 1933, 16, 231-236. WOODBURNE, L. S., \& RIEKE, G. K. Response to symbols by squirrel monkeys. Psychonomic Science, 1966, 5, 429-430. NOTES

1. The present work was based in part on the MS thesis of the first author from the University of Georgia.

2. Address reprint requests to Charles $S$. Noble, Department of Psychology, University of Georgia, Athens, Ga. 30601.

3. Martin, M. Unpublished project, 1966. Cited by $D$. M. Rumbaugh. The learning and sensory capacities of the squirrel monkey in phylogenetic perspective. In L. A. Rosenbloom and R. W. Cooper (Eds.) The squirrel monkey. New York: Academic Press, 1968. Pp. 256-318.

\title{
Sodium deficiency and latent learning ${ }^{1}$
}

RICHARD S. WEISINGER, ${ }^{2}$ STEPHEN C. WOODS, ${ }^{3}$ and JOSEPH D. SKORUPSKI, University of Washington, Seattle, Wash. 98105

Rats were trained to press a lever to obtain a 0.33-M saline solution while thirsty. Later, under extinction conditions, those rats that had been injected with either formalin or aldosterone pressed a
Recently, Krieckhaus \& Wolf (1968) reported that rats could associate a present need state with the consequences of a former situation. In the study, thirsty rats were trained to press a lever to obtain a saline solution $(0.15 \mathrm{M})$. Later, half were injected with formalin and given access to water. Formalin, under these conditions, has been shown to cause hyponatremia and to elicit sodium appetite in rats (Stricker \& Wolf, 1966), when measured $24 \mathrm{~h}$ later. All Ss were put in the lever-pressing situation $24 \mathrm{~h}$ after the injection under extinction conditions (i.e., no reinforcements were received). The formalin-injected rats pressed significantly more times than their vehicle-injected controls.

There are two points worth considering here. The first is that these findings appear to be a clear-cut example of latent learning and are therefore of interest since this type of latent learning is hard to obtain (MacCorquodale \& Meehl, 1954; Krieckhaus \& Wolf, 1968). For this reason, the study is worth repeating.

The second point is that although this enhanced lever pressing seems to imply sodium appetite, Krieckhaus and Wolf state that sodium deficiency is necessary for this enhancement to occur. Yet sodium deficiency has been claimed not to be necessary for sodium appetite (Wolf \& Stricker, 1967).

Aldosterone, like formalin, has been shown to elicit sodium appetite (Wolf, 1964; Wolf \& Handal, 1966). However, aldosterone acts at the kidney to prevent sodium loss (Edelman, 1966). Therefore, it probably results in a positive sodium balance rather than in hyponatremia, since this is the effect of mineral-ocorticoid administration in rats (Friedman, Polley, \& Friedman, 1948). In the present study, aldosterone, as well as formalin, was found to enhance lever pressing during extinction under conditions when the rats had previously pressed for saline. This result indicates that sodium deficiency is not a necessary condition for this phenomenon.

EXPERIMENT 1

\section{Method}

The Ss were eight naive male Wistar rats (90 days old) obtained from the colony maintained by the University of Washington Psychology Department. They were housed in individual cages.

The experimental apparatus consisted of two modified Skinner boxes ( $6 \times 4 \times 5$ in.). On the front wall was a small lever and a fountain. The Skinner boxes were housed in a larger box designed to reduce noise.

Prior to experimentation, all Ss were deprived of water for $23 \mathrm{~h}$ and received liquid thereafter only during the training sessions. All Ss were given 3 consecutive days of training ( $1 \mathrm{~h}$ each day) in which 
Table 1

Lever Presses for the Various Groups in Experiments 1 and 2. PTA refers to pretest average.

\begin{tabular}{lrrr} 
& PTA & $\begin{array}{r}\text { Test } \\
\text { Day }\end{array}$ & $\begin{array}{l}\text { Percent } \\
\text { of PTA }\end{array}$ \\
\hline $\begin{array}{lrrr}\text { Experiment 1 } \\
\text { Formalin }\end{array}$ & 364 & 302 & 83 \\
& 178 & 62 & 35 \\
Water & 153 & 57 & 37 \\
& 444 & 36 & 08 \\
& 636 & 15 & 02 \\
& 299 & 10 & 03
\end{tabular}

\begin{tabular}{crrr} 
Experiment 2 & & & \\
Aldosterone & 168 & 93 & 55 \\
& 344 & 34 & 10 \\
& 284 & 167 & 59 \\
& 214 & 105 & 49 \\
Acetone & 76 & 20 & 26 \\
& 300 & 25 & 08 \\
& 255 & 9 & 04 \\
& 225 & 36 & 16 \\
& 510 & 85 & 17 \\
\hline
\end{tabular}

Table 2

Plasma Sodium Values (in $\mathrm{mEq} / 1$ ) for the Rats in Experiment 3

\begin{tabular}{|c|c|c|c|}
\hline & $\begin{array}{c}\text { Pre- } \\
\text { injection }\end{array}$ & $\begin{array}{c}16 \mathrm{H} \\
\text { Post- } \\
\text { injection }\end{array}$ & $\begin{array}{c}\text { Differ- } \\
\text { ence }\end{array}$ \\
\hline Aldosterone & $\begin{array}{l}140.5 \\
139.5 \\
142.0\end{array}$ & $\begin{array}{l}143.0 \\
139.5 \\
146.5\end{array}$ & $\begin{array}{l}+2.5 \\
+0.0 \\
+4.5\end{array}$ \\
\hline Acetone & $\begin{array}{l}146.0 \\
143.5 \\
146.0\end{array}$ & $\begin{array}{l}144.0 \\
145.0 \\
143.5\end{array}$ & $\begin{array}{l}-2.0 \\
+1.5 \\
-2.5 \\
\end{array}$ \\
\hline
\end{tabular}

they received a $0.33-\mathrm{M}$ saline solution according to the following schedules: Day 1, VI 15; Day 2, VI 30; Day 3, VI 60. Eight hours following the last training session, the Ss were divided randomly into two groups. Ss in the experimental group received a subcutaneous injection of $2.5 \mathrm{ml}$ of $1.5 \%$ formalin; Ss in the control group received $2.5 \mathrm{ml}$ of the vehicle, distilled water. All Ss were then returned to their home cages where ad lib water, but no food, was available. On the following day, $16 \mathrm{~h}$ following the injections, each $\mathrm{S}$ was put in a Skinner box for $1 \mathrm{~h}$ under extinction conditions. The boxes had been washed clean of salt.

\section{Results}

Animals that did not press at least 100 times on the last training session were not used in the analysis. Two Ss failed to reach this criterion. The average number of lever presses each $S$ made on the last 2 days of training was calculated. The number of lever presses made on the test trial (i.e., the extinction trial) for each rat was compared to this pretest average, i.e., a percentage score was calculated for each $\mathrm{S}$.

There were no reliable differences between groups during the training sessions. On the test day, rats that had received formalin injections lever-pressed $51.6 \%$ of their pretest rates, while rats that received the vehicle pressed only $4.3 \%$ of their pretest rates $(t=3.00,4 \mathrm{df}, \mathrm{p}<.05)$. The data are given in Table 1.

\section{EXPERIMENT 2 \\ Method}

Ten Ss of the same type as above were trained according to the same schedules as in Experiment 1. Eight hours following the final training session, half of the rats (selected randomly) received a subcutaneous injection. of $150 \mathrm{micrograms} / \mathrm{kg}$ of d-aldosterone acetate (4-pregnen-18-al-11B, 21-diol-3, 20-dione; Mann Research Laboratories, New York), and the other half received the equivalent volume (approximately $0.30 \mathrm{ml}$, depending upon each S's weight) of the vehicle, acetone. The rest of the procedure is the same as in Experiment 1.

\section{Results}

The data from one $S$ were eliminated for failure to meet the criterion used above. Rats that received aldosterone reached $39.8 \%$ of their pretest rates, while rats that received the vehicle reached $11.2 \%$ of their pretest rates $(t=2.94,7 \mathrm{df}, \mathrm{p}<.05)$. These data are also given in Table 1 .

\section{EXPERIMENT 3 \\ Method}

Six Ss of the same type as above had a blood sample milked from their tails via the method of Woods, Makous, \& Hutton (1969). Half of the rats (randomly selected) then received a subcutaneous injection of $150 \mathrm{micrograms} / \mathrm{kg}$ of d-aldosterone acetate, and half received acetone. All Ss then got $16 \mathrm{~h}$ with water, but no food, as in the other two experiments. Following this period, a second blood sample was taken from each rat. Sodium concentrations were subsequently determined for the plasma portion of the blood samples by emission spectrophotometry. The change in plasma sodium over the $16-\mathrm{h}$ period is the dependent variable of interest.

\section{Results}

Although there were no significant differences between the two groups, the results indicate that if anything, the aldosterone rats are slightly hypernatremic. The data are given in Table 2 .

$$
\text { DISCUSSION }
$$

Experiment 1 confirms the findings of Krieckhaus \& Wolf (1968) that formalin causes enhanced lever pressing in the extinction situation. To label this phenomenon latent learning depends upon the assumption that the rats were not sodium deficient during the training sessions. There is no evidence to indicate that the rats were indeed sodium deficient at that time, unless rats maintained under standard laboratory conditions are chronically sodium deficient.

Experiment 2 shows that aldosterone can also enhance lever pressing in the extinction situation. Experiment 3 indicates that rats given aldosterone and maintained on the same drinking conditions as the rats in Experiment 2 may actually by hypernatremic, and are certainly not sodium deficient. An explanation other than sodium deficiency is therefore necessary to explain the enhanced lever pressing in the extinction situation.

Formalin and aldosterone both cause sodium appetite (Wolf \& Stricker, 1967), although only formalin lowers body sodium. Therefore, perhaps the physiological conditions necessary to elicit sodium appetite are also the conditions necessary to elicit enhanced lever pressing in the present situation.

\section{REFERENCES}

EDELMAN, 1. S. Subcellular distribution and mode of action of aldosterone. In G. Pincus, N. Takeshi, and J. F. Tait (Eds.), Steroid dynamics. New York: Academic Press, 1966. Pp. 551-568.

FRIEDMAN, S. M., POLlEY, J. R., \& FRIEDMAN, C. L. The effect of desoxycorticosterone acetate on blood pressure, renal function, and electrolyte pattern in the intact rat. Journal of Experimental Medicine, 1948, 87, 329-338.

KRIECKHAUS, E. E., \& WOLF, G. Acquisition of sodium by rats: Interaction of innate mechanisms and latent learning. Journal of Comparative \& Physiological Psychology, 1968, 65, 197-201.

MacCORQUODALE, K., \& MEEHL, P. E. Edward C. Tolman. In W. K. Estes, S. Koch, K. MaoCorquodale, P. E. Meehl, C. G. Mueller, Jr., W. N. Schoenfeld, and W. S. Verplanck (Eds.), Modern learning theory. New York Appleton-Century-Crofts, 1954. Pp. 177-266.

STRICKER, E. M., \& WOLF, G. Blood volume and tonicity in relation to sodium appetite. Journal of Comparative \& Physiological Psychology, 1966, 62, 275-279.

WOLF, G. Sodium appetite elicited by aldosterone. Psychonomic Science, 1964, 1, 211-212.

WOLF, G. \& HANDAL, P. J. Aldosterone-induced sodium appetite: Dose-response and specificity. Endocrinology, $1966,78,1120-1124$.

WOLF, G., \& STRICKER, E. M. Sodium appetite elicited by hypovolemia in adrenalectomized rats: Reevaluation of the "reservoir" hypothesis. Journal of Comparative \& Physiological Psychology, 1967, 63, 252-257. WOODS, S. C., MAKOUS, W., \& HUTTON, R. A. Temporal parameters of conditioned hypoglycemia. Journal of Comparative \& Physiological Psychology, 1969, 69, 301-307. NOTES

1. This study was supported in part by USPHS Training Grant 5T01 GM 00666 and in part by NSF Grant GB 8035.

2. Requests for reprints should be addressed to Richard S. Weisinger, Department of Psychology, University of Washington, Seattle, Wash. 98105. 3. USPHS Predoctoral Fellow. 